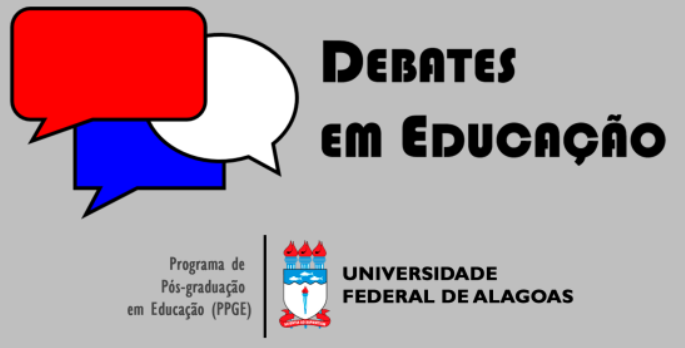

ISSN Eletrônico 2175-6600

Vol. 12 | Edição Especial | 2020

Silvio Profirio da Silva

9 iD

Prefeitura da Cidade de Vitória de Santo Antão (PVSA)

profirio.silvio@bol.com.br

Suzana Teixeira de Queiroz

9 iD

Prefeitura da Cidade do Recife (PCR) queiroz.suzana@yahoo.com.br

Josete Marinho de Lucena

9 iD

Universidade Federal da Paraíba (UFPB)

josetemarinho.ufpb@gmail.com

\section{ENTREVISTA COM A PROFESSORA DRA. MARIA AUXILIADORA BEZERRA: A EVOLUÇÃO HISTÓRICA DO TRABALHO PEDAGÓGICO E DOS MATERIAIS DIDÁTICOS DE LÍNGUA PORTUGUESA EM FOCO}

\section{RESUMO}

Este trabalho contextualiza os resultados de uma entrevista realizada com a Professora Maria Auxiliadora Bezerra acerca da evolução histórica do trabalho pedagógico do ensino de língua materna, bem como sobre a evolução histórica dos materiais didáticos de Língua Portuguesa. A entrevistada é Doutora em Estudos Linguísticos Româncios, com foco no âmbito da Sociolinguística e da Dialetologia Românicas pela Université de Toulouse-le Mirail. Por dezenove anos, foi professora da Universidade Federal da Paraíba - UFPB (1977-1996), onde atuou na Graduação em Letras e na Pós-Graduação em Linguística (Mestrado e Doutorado). Desde 2002, é professora da Universidade Federal de Campina Grande - UFCG, atuando na graduação e na pós-graduação. Suas produções acadêmicas estão concentradas no âmbito da Linguística Aplicada, focando, sobretudo, nas seguintes temáticas: ensino de língua materna, ensino da leitura e da escrita, percurso histórico da metodologia do ensino de língua materna no Brasil, evolução histórica dos livros didáticos de Língua Portuguesa no Brasil, avaliação da aprendizagem, léxico etc. Possui diversos artigos científicos publicados, bem como diversos livros organizados no campo da Linguística Aplicada, entre eles, podemos destacar: "O Livro Didático de Português: múltiplos olhares", "Gêneros Textuais e Ensino", "Análise Linguística: afinal, a que se refere?", "Estudar Vocabulário: como e para quê?" etc.

Palavras-chave: Língua materna. Metodologia de ensino. Materiais didáticos. Evolução histórica.

Submetido em: 25/09/2019

Aceito em: $25 / 11 / 2019$

Publicado em: 10/12/2020

do http://dx.doi.org// 0.28998/2 175-6600.2020v I 2nEspp643-653 


\section{BREVE CONTEXTUALIZAÇÃO DA ENTREVISTA}

No dizer de Silva e Morais (20 I I), a tarefa de ensinar língua materna, por um amplo contingente de tempo, limitou-se à atividade de abordar compêndios gramaticais, recorrendo, para tal, à efetivação de metodologias canalizadas na análise e na classificação de trechos frasais. Nos dias hodiernos, sob a perspectiva sócio-interacional de linguagem, o trabalho pedagógico do ensino de língua materna prima pela reflexão e pelo uso, propondo-se a formar usuários competentes da língua. Diante dessa acepção, hoje, o ensino de língua materna transcende a roupagem da metalinguagem.

Um amplo contingente de pesquisadores do âmbito dos Estudos da Linguagem [Santos (2002), Perfeito (2007), Pietri (2007), Costa-Hübes (2009, 20 I I) etc.], bem como no âmbito da Pedagogia [Albuquerque, (2006), Albuquerque, Morais e Brito (2008), Silva e Morais (20 I I) entre outros.] apontam os anos de 1980 como um momento histórico, no tocante ao trabalho pedagógico do ensino de língua materna. Em tal momento, é fomentado um processo de disseminação de um leque de postulados linguísticos (Análise do Discurso, Análise da Conversação, Linguística de Texto, Pragmática, Sociolinguística etc.), cujo cerne não são mais a forma e a estrutura da língua. Em vez de primar pela descrição da forma, tais postulados materializam uma perspectiva de linguagem como interlocução.

Esse processo de disseminação de postulados refrata o tratamento concedido às metodologias de ensino, bem como aos materiais didáticos de língua materna presentes no contexto escolar. Em outras palavras, sob o influxo da proliferação dos postulados sociointeracionistas da linguagem, o trabalho pedagógico do ensino de língua materna, assim como os materiais didáticos (em especial, os livros didáticos) veem, continuamente, vivenciando um intenso contexto de comutação, como ressalta Silva (2017).

Bunzen (2007), por exemplo, aponta os elementos propulsores de comutações na organização dos conteúdos e na estruturação interna dos livros didáticos de língua. No dizer do referido autor, o influxo da Teoria da Comunicação e da Concepção de Linguagem como Instrumento de Comunicação acarretou uma "abertura textual" nas rotinas educacionais, oportunizando a inserção dos gêneros do âmbito jornalístico e do âmbito midiático no trabalho didático do ensino de língua materna. Como o ensino de língua materna passou a conceder primazia à exploração das funções da linguagem e dos elementos da comunicação, os gêneros jornalísticos e midiáticos passaram a ser usados nas rotinas educacionais, assim como nos livros didáticos. Isso erradicou a supremacia concedida aos gêneros do âmbito literário.

Outro fator propulsor das comutações na organização de conteúdos e na estruturação interna dos livros didáticos de língua apontado por Bunzen (2007) refere-se aos postulados críticos do letramento, assim como aos postulados respeitantes aos gêneros discursivos. Tais estudos colocaram em notoriedade os gêneros dos discursos e sua funcionalidade dentro de distintas situações comunicativas de uso. Diante 
desse quadro, os gêneros ganharam o estatuto de objetos de ensino, subsidiando a promoção de situações de aprendizagem canalizadas na apropriação do funcionamento discursivo desses gêneros. Na ótica de Bunzen (2007, p. 45),

Os estudos críticos do letramento e os estudos sobre gêneros do discurso, nos anos 90, que enfocavam a relação entre os textos e seu funcionamento em práticas sociais situadas, contribuem também para esse processo. Os conceitos de letramento e gênero, aliados à discussão de diversificação das situações de produção e de circulação de textos na escola (e fora dela), aparecem como elementos centrais nos Parâmetros Curriculares Nacionais e, consequentemente, nos livros didáticos pós-PCN. Não podemos esquecer que o próprio documento oficial legitima um trabalho que prevê organização das situações de aprendizagem a partir da diversidade textual e reconhece os gêneros como objetos de ensino, sugerindo, inclusive, um agrupamento para cada ciclo do ensino fundamental em função da esfera de circulação social (literários, de imprensa, publicitários e de divulgação científica).

Por último, Bunzen (2007) aponta o influxo do Programa Nacional de Avaliação do Livro Didático (PNLD) para as modificações realizadas na organização de conteúdos e na estruturação interna dos livros didáticos de língua. Para o autor, o PNLD ampliou de modo considerável o contingente de gêneros discursivos no corpo estrutural dos livros didáticos de Língua Portuguesa. Além disso, tal programa aumentou, consideravelmente, o quantitativo de temáticas, bem como o quantitativo da diversidade de esferas sociocomunicativas, de suportes e de semioses.

Ao pensarmos no que motiva as modificações ao longo dos anos na configuração do ensino de língua materna, vemos que há uma necessidade proeminente de se aprimorar leitura e produção de texto para usos sociais da linguagem. E, apesar dos avanços alcançados no ensino de língua materna, ainda não conseguimos mobilizar o/a aluno/a a perceber que o que ele aprende na escola (sobretudo, a leitura e a escrita) tem o intuito de ser usado fora do espaço escolar, como asseveram Guedes e Souza (2000).

Essas são apenas algumas alterações ocorridas na organização estrutural dos livros didáticos de Língua Portuguesa. Cientes da extrema relevância desse material didático na efetivação de um trabalho pedagógico voltado para a formação de usuários competentes da língua e diante de diversas inquietações acerca dos materiais didáticos presentes nas rotinas educacionais, realizamos entrevista com uma autoridade no âmbito dos Estudos da Linguagem com foco no percurso histórico da metodologia do ensino de língua e dos livros didáticos de língua. Reportamo-nos, então, à Professora Doutora Maria Auxiliadora Bezerra.

A entrevistada é Doutora em Estudos Linguísticos Româncios, com foco no âmbito da Sociolinguística e da Dialetologia Românicas pela Université de Toulouse-le Mirail. Por dezenove anos, foi professora da Universidade Federal da Paraíba - UFPB (1977-1996), onde atuou na Graduação em Letras e na Pós-Graduação em Linguística (Mestrado e Doutorado). Desde 2002, é professora da Universidade Federal de Campina Grande - UFCG, atuando na graduação e na pós-graduação. Suas produções acadêmicas estão concentradas no âmbito da Linguística Aplicada, focando, sobretudo, nas seguintes temáticas: ensino de língua materna, ensino da leitura e da escrita, percurso histórico da metodologia do 
ensino de língua materna no Brasil, evolução histórica dos livros didáticos de Língua Portuguesa no Brasil, avaliação da aprendizagem, léxico etc. Possui diversos artigos científicos publicados, bem como diversos livros organizados no campo da Linguística Aplicada, entre eles, podemos destacar: "O Livro Didático de Português: múltiplos olhares", "Gêneros Textuais e Ensino", "Análise Linguística: afinal, a que se refere?", "Estudar Vocabulário: como e para quê?" etc.

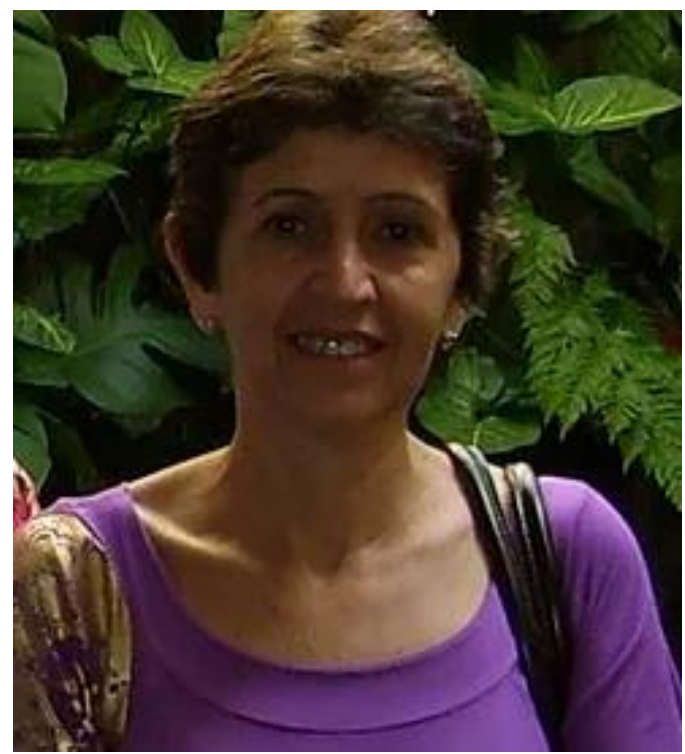

Fonte: A entrevistada (2019). 


\section{A ENTREVISTA COM A PROFESSORA DR ${ }^{\mathrm{a}}$. MARIA AUXILIADORA BEZERRA}

\section{Entrevistadores: Antes do surgimento dos livros didáticos de Língua Portuguesa, os docentes faziam uso de Antologias. Diante disso, como podem ser definidas as Antologias?}

Maria Auxiliadora Bezerra: Sabemos que antologia, na área de Literatura, é um conjunto de textos em prosa ou verso, selecionados conforme critérios estabelecidos para leitura e apreciação, tais como: autor, época, estilo, tema, entre outros. Tanto antes de a disciplina Língua Portuguesa ter sido incluída na escola secundária (o que ocorreu por volta de 1870), quanto depois dessa inclusão, a antologia exercia um papel fundamental, pois possibilitava o contato dos alunos com a Literatura canônica e, consequentemente, com a língua dita 'correta', 'exemplar', 'bela'. Assim, o estudo da antologia com o da gramática normativa garantia o domínio da língua culta pelos estudantes. A antologia mais conhecida e estudada nas escolas brasileiras, antes dos livros didáticos se disseminarem, foi a Antologia Nacional, da autoria de Fausto Barreto e Carlos de Laet, publicada desde o século XIX até o século XX (sua última edição foi em 1969). Os textos que compunham essa Antologia eram de autores portugueses e brasileiros do século XVI ao XX, iniciando-se com os textos mais recentes (de autores brasileiros) e finalizando com os mais antigos, tanto de escritores brasileiros, quanto de portugueses.

\section{Entrevistadores: Qual a concepção de linguagem e de texto subjacente às Antologias? Quais os gêneros abordados nesse material didático?}

Maria Auxiliadora Bezerra: Na época das antologias, escrever era expressar o pensamento no papel. Essa concepção de escrita reflete a de linguagem, entendida como expressão do pensamento, das intenções, dos sentimentos de quem escreve, desejando que o leitor entenda o que the está sendo dito. Assim, vemos a linguagem como um recurso que proporciona ao escritor expor suas ideias. E os textos eram entendidos como o produto da escrita, a demonstração concreta dessas ideias do autor e, por conseguinte, a demonstração de que o escritor também domina a linguagem que usa, podendo, inclusive, fugir às regras da gramática normativa, o que se caracterizava como 'licença poética'. Os gêneros predominantes nas antologias eram - em prosa - romance, novela (excertos), fábula, crônica; em verso - poemas variados. Todos eram selecionados sob o critério de canonicidade, visto que o fim último das antologias era apresentar modelos de língua exemplar. 
3 Entrevistadores: Como o professor de Língua Portuguesa utilizava as Antologias no trabalho pedagógico?

Maria Auxiliadora Bezerra: As antologias eram utilizadas juntamente com as gramáticas normativas. Aquelas eram indicadas para leitura e apreciação dos textos literários consagrados pela crítica e para o estudo de suas características (preferencialmente, partia-se dos estilos de época). As gramáticas eram estudadas para classificação e reconhecimento das unidades linguísticas e suas estruturas: um estudo metalinguístico. Visto que, para ser professor de Língua Portuguesa, na época das antologias, bastava ser conhecedor da Literatura e das classificações dadas pela gramática normativa. As antologias eram utilizadas com mais profundidade de análise pelo professor afeito à Literatura e menos por aquele mais dedicado aos preceitos gramaticais.

4 Entrevistadores: Em um dos capítulos do livro "Livro Didático de Português: múltiplos olhares", a senhora destaca o fato de que os primeiros manuais didáticos relativos a esse componente curricular emergiram no final da década de 1960 e início da década de 1970. Diante dessa constatação, como era a organização estrutural interna desses primeiros manuais? Que eixos didáticos eram contemplados nesses primeiros manuais?

Maria Auxiliadora Bezerra: A organização estrutural dos primeiros livros didáticos de Português parecia ser um acoplamento da antologia com a gramática, em um só volume. Cito, por exemplo, "Português no ginásio" e "Português no Colégio" de Raul Moreira Léllis, publicado pela Editora Companhia Nacional. Há edição de 1960, 1965, 1967. O primeiro livro didático ("Português no ginásio") era usado no ginásio (atual Ensino Fundamental - Anos Finais). O segundo livro ("Português no Colégio"), por sua vez, era utilizado no científico e clássico (atual Ensino Médio). Os textos literários eram acompanhados de informações bibliográficas sobre seus autores; um pequeno glossário (ou vocabulário) com termos (retirados dos textos) presumivelmente desconhecidos pelos alunos e perguntas sobre a temática e o estilo dos textos. A gramática continuava sendo estudada segundo as classes e formação de palavras; análise sintática do período e da oração; noções de fonética (principalmente no livro do último ano do Ginásio, atualmente, Ensino Fundamental); versificação e estilística. Em suma, a organização interna dos livros contemplava leitura, gramática normativa e exercícios. 


\section{Entrevistadores: Quais as concepções de linguagem e de textos} implícitas na constituição dos primeiros livros didáticos de Língua Portuguesa? Quais gêneros textuais eram abordados nesses primeiros manuais didáticos? Como era a seleção temática?

Maria Auxiliadora Bezerra: As concepções eram as mesmas que subjaziam às antologias e gramáticas. Só havia uma forma correta de usar a língua e essa forma era demonstrada pelos textos literários canônicos, isto é, expressar o pensamento de maneira clara e correta. Quanto mais corretas fossem a fala e a escrita, mais claro era o pensamento do autor e o inverso. Quanto mais errados estivessem o texto escrito e a fala (distantes do modelo eleito como correto), mais demonstravam um pensamento confuso do autor. Ou seja, não saber escrever/falar bem significava não saber pensar claramente, porque quem pensa com clareza escreve corretamente. Os gêneros eram romances, contos, histórias (excertos), fábulas, provérbios, máximas (por exemplo, as de Marquês de Maricá), sonetos, epopeia (excertos) e outros poemas. Na década de 1970, começou-se a estudar outros gêneros, além dos literários, como história em quadrinhos, canções, textos jornalísticos. Isso, porque a concepção de linguagem que as pesquisas universitárias difundiam era a de Instrumento de Comunicação (influência da Linguística e das Teorias de Comunicação nos estudos de Língua Portuguesa). Nessa mesma década, instituiu-se o livro do professor, além do livro do aluno, distinguindo-se desse porque continha as respostas dos exercícios. A seleção temática tinha como critério de destaque princípios morais e cívicos (moral, ética, virtude, nacionalismo, respeito à pátria e a seus símbolos..). Não podemos esquecer que, em parte, esses temas foram herdados das antologias e, em parte, foram enfatizados, nos anos de 1960 e 1970, por causa da ditadura militar que se instituiu na Brasil, em 1964.

\section{Entrevistadores: Qual é o papel das abordagens teóricas dos postulados linguísticos propalados na década de 1980 na moldagem do trabalho pedagógico do ensino de Língua Portuguesa?}

Maria Auxiliadora Bezerra: Os estudos psicolinguísticos de leitura, os estudos dialógicos de língua começavam a se difundir no Brasil, nessa década de 1980, e concepções estritamente linguísticas ou gramaticais passaram a ser questionadas (língua como Instrumento de Comunicação e, consequentemente, escrita e leitura como atos de codificar e decodificar, respectivamente; estudo metalinguístico da língua; conceitos de certo/errado, à luz da gramática normativa; saber bem essa gramática é condição primeira para se escrever bem). A leitura era compreendida como uma atividade 
cognitiva; a língua, concebida como forma de interação entre interlocutores. Logo, parecia não haver lugar para o ensino normativo da língua. Variados textos deveriam ser propostos para leitura. Reflexos desses estudos teóricos passaram a ser identificados nos livros didáticos no final dessa década, mas, principalmente, a partir dos anos 1990. A seção de leitura dos livros didáticos se ampliou, incluindo textos verbais (literários e não literários) e não verbais, questões metacognitivas e interpretativas - além das de decodificação; e a metalinguagem da gramática normativa foi perdendo seu vigor. A configuração do livro do aluno passou a ter as seções de leitura e interpretação. Redação e gramática escassearam. Desapareceram estudos de fonética, versificação e estilíistica. E o livro do professor permaneceu com as respostas aos exercícios, mas foi ganhando informações teóricas, visando a fundamentar esse profissional sobre a proposta de ensino de leitura e de gramática. Os professores em serviço, que não tinham conhecimento desses novos modelos teóricos, precisaram se atualizar para utilizarem os novos livros a contento. Foi, nesses anos 1990, que a formação continuada de professores teve grande impulso, continuando até hoje, ao lado da formação inicial.

\section{Entrevistadores: Em virtude dos mais recentes postulados da linguagem, qual o objeto de ensino de Língua Portuguesa nos dias de hoje?}

Maria Auxiliadora Bezerra: Na década de 1990, o MEC criou, no âmbito das políticas públicas para a educação brasileira, o Programa Nacional do Livro Didático (PNLD) com o objetivo de avaliar a produção editorial desses livros. A avaliação tinha como finalidade última orientar esse Ministério para a compra de livros didáticos a serem distribuídos nas escolas públicas. Essa avaliação terminou por induzir mudanças na elaboração dos livros, visto que os fundamentos teóricos que orientavam a avaliação provinham de teorias sociointeracionistas da linguagem, teorias de letramento (difundidas na década de 1990) e, posteriormente, de gêneros textuais/discursivos (década de 2000). Essas teorias descrevem a língua em seus contextos sociais, observando seus usos e funcionamento. Nesse contexto, a orientação dada ao ensino de Língua Portuguesa foi a de abordar a língua em seus usos efetivos. As teorias de leitura, de escrita, de oralidade (essa última, principalmente com contribuições norte-americanas sobre estudos da língua falada) foram orientando o modelo de livro didático de Português que se queria no Brasil (o modelo da ficha, proposta pelo PNLD, para a avaliação dos livros teve papel decisivo no formato do livro didático atual). Assim, temos como eixos de ensino a leitura (abordada à luz dos múltiplos letramentos existentes na sociedade), a escrita (fundamentada nos letramentos e nas teorias de gêneros textuais/discursivos), a oralidade (também baseada nas mesmas teorias citadas, mas ainda pouco explorada, se compararmos com os eixos anteriores) e os conhecimentos linguísticos/gramaticais (o eixo menos desenvolvido e, por isso, mais flutuante no ensino efetivo, levando uns professores a permanecerem com o estudo gramatical da tradição greco-latina 
e outros a eliminarem-no, não se enfatizando nem os conhecimentos linguísticos em prol da leitura ou da escrita). De fato, o objeto de ensino de Língua Portuguesa na Educação Básica corresponde às competências de leitura, escrita e oralidade e, com menor ênfase, as unidades menores da língua (sintagmas, morfemas e fonemas).

\section{Entrevistadores: Como os estudos sobre o texto e discurso, assim como os estudos tocantes ao letramento ocasionaram modificações na organização estrutural interna dos livros didáticos de Língua Portuguesa? Quais as modificações que esses estudos acarretam?}

Maria Auxiliadora Bezerra: De certa forma, a resposta a essa questão já se encontra um pouco no que eu disse acima (questão 7), mas há outros aspectos que podem ser citados. Acredito que os postulados relativos a discurso ainda não influenciam os livros didáticos, talvez devido à dificuldade de se estudar o discurso (considerando as diversas concepções que há desse termo), visto que é por meio do texto que alcançamos o discurso. Assim, essa materialidade, que é o texto, torna-se mais palpável para seu estudo. Um exemplo é a influência da Linguística Textual no estudo de textos nos livros didáticos: critérios de textualidade (principalmente, coesão e coerência), progressão temática, referenciação e outros tópicos. As teorias de letramento influenciam o ensino de leitura, de escrita, de oralidade, sobretudo quando o livro didático considera os múltiplos letramentos, tais como: o literário, o profissional, o digital, o escolar, entre outros, o que possibilitou ao aluno ultrapassar os muros da escola e desenvolver os projetos de letramento propostos nos livros. Observo que a estrutura desses livros contempla capítulos, ou unidades, ou módulos, que se iniciam com propostas de leitura de textos artísticos (quadros de pintura, escultura, fotos, etc.) para, em seguida, continuar com textos literários, ou teatrais, ou jornalísticos ou científicos, buscando alcançar o objetivo de desenvolver os letramentos do aluno. Ao mesmo tempo, há a inclusão de materiais digitais (CD, por exemplo) e indicações de sites, de filmes, de vídeos para os alunos consultarem/assistirem, a fim de ampliarem seus conhecimentos. Em relação à produção de textos, esses, muitas vezes, não são mais destinados simplesmente ao professor, que os corrigirá. Os textos têm destinatários variados. Sua correção e reformulação têm o objetivo de torná-los adequados à situação comunicativa a que se destinam. Resumindo, os livros continuam organizados em seções, mas, no interior delas, há alterações motivadas pelas teorias que fundamentam a proposta de ensino de Língua Portuguesa. 


\section{Entrevistadores: Nos dias de hoje, como os Livros Didáticos de Língua Portuguesa contemplam os eixos de ensino (leitura, escrita, oralidade e análise linguística)?}

Maria Auxiliadora Bezerra: Acredito que esta pergunta também já foi respondida ao longo da entrevista. Embora haja um esforço por parte dos autores desses livros para explorar todos os eixos de ensino, noto que ainda predominam os da leitura e da escrita. $O$ de oralidade vem se ampliando, principalmente, com gêneros mais facilmente adaptados para atividades didáticas (por exemplo, seminário, exposição oral, debate). No entanto, ainda há muitas atividades que solicitam do aluno apenas "conversar" com os colegas sobre um determinado assunto/fato dado (ou seja, não se trata efetivamente de ensino do uso da oralidade em situações públicas formais). E o eixo dos conhecimentos linguísticos, a meu ver, é o que tem menos investimento: ora explora a metalinguagem e as classificações da gramática tradicional - nesse caso, se restringe à reprodução de um conhecimento restrito, porque voltado apenas para uma variedade de língua não totalmente condizente com o Português brasileiro - ora explora conhecimentos advindos da Linguística - nesse caso, voltados para as concepções de linguagem e de signo, funções da linguagem (com base em teorias linguísticas diversas), para o texto (com a Linguística Textual, principalmente) e para unidades linguísticas do tipo morfema, sintagma (utilizando-se os termos oriundos da Linguística, mas com a descrição da gramática tradicional, num processo de sobreposição). Embora os livros didáticos ainda não demonstrem equilíbrio na exploração dos eixos de ensino, apresentam uma grande melhoria, se comparados com o que havia na década de 1980.

\section{REFERÊNCIAS}

\section{ALBUQUeRQUE, E. B. C. Mudanças Didáticas e Pedagógicas no Ensino da Língua Portuguesa:} apropriações de professores. Belo Horizonte: Autêntica, 2006.

ALBUQUERQUE, E. B. C.; MORAIS, A. G.; FERREIRA, A. T. B.As práticas cotidianas de alfabetização: o que fazem as professoras?. Revista Brasileira de Educação, v. 13, p. 252-264, 2008. Disponível em: http://www.scielo.br/pdf/rbedu/v13n38/05.pdf. Acesso em: 30 set. 2019.

BUNZEN, C. O tratamento da diversidade textual nos livros didáticos de português: como fica a questão dos gêneros?. In: SANTOS, C. F.; MENDONÇA, M.; CAVALCANTI, M. (Org.). Diversidade Textual: os Gêneros na sala de aula. Belo Horizonte: Autêntica, 2007. p. 43-58.

COSTA-HÜBES, T. C. Reflexões linguísticas sobre metodologia e prática de ensino em Língua Portuguesa. Confluência, v. I, p. 129- 146, Rio de Janeiro, 2009. Disponível em: http://lp.bibliopolis.info/confluencia/pdf/742.pdf. Acesso em: I 5 set. 2019. 
COSTA-HÜBES, T. C. Por uma concepção sociointeracionista da Linguagem: orientações para o ensino da Língua Portuguesa. Línguas \& Letras, v. I, p. I-19, 201 I. Disponível em: http://erevista.unioeste.br/index.php/linguaseletras/article/view/5486. Acesso em: 13 set. 2019.

GUEDES, P.C.; SOUZA, J. M. Leitura e escrita são tarefas da escola e não só do professor de português. In: NEVES, I.C.B.; SOUZA, J. V. (Orgs.). Ler e Escrever: compromisso de todas as áreas. Porto Alegre: Ed. UFRGS, 2000.

LÉLLIS, R. M. Português no Colégio. São Paulo: Companhia Editora Nacional, 1963.

LÉLLIS, R. M. Português no Ginásio: Gramática e Antologia. São Paulo: Companhia Editora Nacional, 1960.

PERFEITO, A. M. Concepções de Linguagem, análise linguística e proposta de intervenção. In: Anais do I Congresso Latino-Americano de Professores de Línguas - CLAPFL, Florianópolis, EDUSC, 2007. Disponível em: http://www.cce.ufsc.br/ clafpl/74 Alba_Maria_Perfeito.pdf. Acesso em: 22 set. 2019.

PIETRI, E. Circulação de saberes e mediação institucional em documentos oficiais: análise de uma proposta curricular para o ensino de língua portuguesa. Currículo sem Fronteiras, v. 7, n. I, p. 263-283, 2007. Disponível em: http://www.curriculosemfronteiras.org/vol7iss I articles/pietri.pdf. Acesso em: 07 set. 2019.

SANTOS, C. F. Formação em serviço do professor e as mudanças no ensino de língua portuguesa. Educação Temática Digital - ETD, Campinas, vol. 3, n. 2, p. 27-37, 2002. Disponível em: http://periodicos.sbu.unicamp.br/ojs/index.php/etd/article/view/605/0. Acesso em: 19 set. 2019.

SILVA, A.; MORAIS, A. G. Entre tradição e inovação: um estudo sobre mudanças no ensino de gramática em livros didáticos brasileiros de Língua Portuguesa. Revista Portuguesa de Educação, v. 24, p. 119-144, 20 I I. Disponível em: http://revistas.rcaap.pt/rpe/article/view/3043. Acesso em: 10 set. 2019.

SILVA, S. P. A Compreensão de Texto na Coleção Português Linguagens - Ensino Médio (1994-20 I3): evolução histórica e perspectivas atuais em debate. Dissertação de Mestrado - Programa de PósGraduação em Linguística e Ensino - Universidade Federal da Paraíba - UFPB, 2017. Disponível em: http://tede.biblioteca.ufpb.br/bitstream/tede/9227/2/arquivoototal.pdf. Acesso em: 02 out. 2019.

\section{COMO CITAR ESSE ARTIGO}

\section{Associação Brasileira de Normas Técnicas (ABNT)}

SILVA, Silvio Profirio da; QUEIROZ, Suzana Teixeira de; LUCENA, Josete Marinho de. Entrevista com a Professora Dra. Maria Auxiliadora Bezerra: a evolução histórica do trabalho pedagógico e dos materiais didáticos de Língua Portuguesa em foco. Debates em Educação, Maceió, v. I2, p. 643-653, 2020. ISSN 2175-6600. Disponível em: https://www.seer.ufal.br/index.php/debateseducacao/article/view/8804. Acesso em: dd mmm. aaaa.

\section{American Psychological Association (APA)}

Silva, S., Queiroz, S., \& Lucena, J. (2020). Entrevista com a Professora Dra. Maria Auxiliadora Bezerra: a evolução histórica do trabalho pedagógico e dos materiais didáticos de Língua Portuguesa em foco. Debates em Educação, 12(Esp), 643-653. doi: https://doi.org/l 0.28998/21756600.2020v12nEspp643-653 